\title{
Acoustic impact of an urban micro hydro scheme
}

\author{
Neil Johnson ${ }^{* 1}$, Jian Kang ${ }^{1}$, Steve Sharples ${ }^{1}$, Abigail Hathway ${ }^{2}$, Papatya Dökmeci ${ }^{1}$ \\ ${ }^{1}$ School of Architecture, University of Sheffield, Sheffield, UK \\ ${ }^{2}$ School of Civil and Structural Engineering, University of Sheffield, Sheffield, UK \\ *Corresponding author. Tel: +44 7534916870, E-mail: arq09nj@sheffield.ac.uk
}

\begin{abstract}
Micro hydro systems can be regarded as a renewable energy source resulting from the natural hydrological cycle, it is by some considered sustainable due to the lack of impoundment of water and assumed negligible environmental impact. Experience with wind energy has highlighted that as the uptake of renewable energy technologies increases so government policies need to keep pace if public complaints and rejection of these technologies is to be averted. Studies on micro hydropower, particularly in an urban setting where propagation of noise is a planning issue, have been very limited. This paper focuses on the acoustic environmental impacts of micro hydropower considering a Reverse Archimedean Screw (RAS). Acoustic samples were taken directly above the RAS, and on a $5 \mathrm{~m}$ interval along a transect and then at, $30 \mathrm{~m}$ and $60 \mathrm{~m}$ along another transect. Two further transects were considered and sampling was made at $30 \mathrm{~m}$ and $60 \mathrm{~m}$. Initial results indicate that during normal operation at $25 \mathrm{~kW}$ the screw would be barely perceptible beyond $60 \mathrm{~m}$; the weir provides significant masking of the turbine noise. It also shows that the noise generated is directional in nature at this site.
\end{abstract}

Keywords: Micro hydro, Acoustics, Noise, Renewable energy, Environmental impact.

\section{Introduction}

It is widely recognised that worldwide energy demand and use is continuing on an apparent, unceasingly ascending trend as, rapid population growth, economic development and therefore inherent demand for fuel increases [1, 2]. The world energy mix is depicted by the International Energy Agency (IEA). According to their World Energy Outlook (2008) [3]; renewables accounted for around 13\% of global energy in 2006. This figure is predicted to rise to around 14\% in the IEA 2030 reference scenario; and 24\% in the IEA 450 (2030) policy scenario (based on policies under consideration). Oil and gas shares are predicted to be around 50\% in both 2030 scenarios whilst coal lost some of its market share to an increase in the use of renewables (including biomass and waste), and nuclear energies.

The role of hydropower as a renewable resource varies dependent on the scale of the installation. As discussed by Frey and Linke [5], many legislative organisations do not consider large-scale hydro power to be a renewable resource when determining eligibility for government support. However, as argued in the paper, this is not a question of renewability but of sustainability. Although micro and pico hydro systems are assumed to be more environmentally friendly due to the lack of impoundment of water and assumed negligible environmental impact [4-6] emerging literature indicates that detrimental environmental impacts can be caused by smaller scale schemes [4].

Paish (2002) [4] indicates that small scale hydro developments in Europe will be the main area for hydro development in the future as the majority of large scale sites have already been exploited and micro hydro schemes seem to be growing in development and government support in the UK $[2,6]$. In the urban setting, the issue of noise generation from visible systems can be a significant factor in the viability of the scheme, and the time period over which it is run. As part of a wider on-going research on the above issues, this paper will focus on initial results from a study of the impacts of a hydro scheme on the acoustic environment. 
As there is recognised potential for hydro schemes in cities due to existing infrastructure, it would appear that there is need for such a study.

Three sites (semi-rural) within the UK using a Reverse Archimedean screws (RAS) to generate electrical power have already been identified as causing a noise nuisance. However, this tends to be associated with poor installation/design faults rather than general noise nuisance during normal operation. Any noise nuisance, whether design faults or operational, may be escalated within a densely populated and built-up urban setting. If micro-hydro is to penetrate into our cities then noise evaluation will become a key issue in the planning and design of such schemes. An extensive but not exhaustive literature search has demonstrated that this type of research has yet to be undertaken. Government policies may need to change to support these technologies and make them more viable; however, evidence is required to enable the government to establish the true impact on the environment of such technologies.

It is known that hydropower sites are most efficient at a particular speed, head and flow [4]. However, the relationship between the power output, river flow and sound power levels is not known. The following study will present measurements taken in the field to evaluate the sound generated from a RAS scheme in New Mills, running at a power output of $25 \mathrm{~kW}$, with a total head of $3+$ metres, and in comparison to the existing sound produced by water flowing over a weir.

\section{Methodology}

Acoustic measurements were carried out around a $2.6 \times 11 \mathrm{~m}$ tri-blade RAS, with a fixed rotation of $28.03 \mathrm{~min}^{-1}$ generating at $25 \mathrm{~kW}$ and a river flow of around $2.17 \mathrm{cumecs}$, located in a parkland setting, within an urban environment. Figures 1 and 2 show plans, and photos of the site respectively. There do not appear to be any standards, or current methods for acoustic sampling of micro hydro turbines in the field in the UK possibly the world. It was therefore prudent to utilize BS 7445 and BS 4142 and the field site's complex geography to design a sampling strategy. Acoustic samples were taken along transects shown in figure 1. All samples were taken at $1.4 \mathrm{~m}$ above the ground surface and where possible over $3 \mathrm{~m}$ away from any facades. Acoustic samples were also taken directly above the RAS to enable the sound power level to be derived. On transects (a), (b) and (c) samples were taken at $30 \mathrm{~m}$ and $60 \mathrm{~m}$ from the RAS. Transects (b) and (c) also included a sample at $90 \mathrm{~m}$. Samples were then taken at $5 \mathrm{~m}$ intervals along transect (d). Sampling directly to the side of the RAS was deemed unsuitable due to the presence of a wall. Figure 2 is a photo of the site taken from above; the right hand image shows the bridge from which it was taken

After numerous visits, it was determined that the site's acoustic characteristics do not alter significantly over time. However, a sample of the acoustic environment was carried out using WinMLS (Windows Maximum Length Sequence), at a fast sampling rate to determine the required acoustic sampling time at each sampling instance. Two minute samples were deemed sufficient for this study.

In addition to the acoustic sampling, figure 1 also, shows the location of two pressure gauge sensors, which have been installed to allow future work on river flows, efficiency and acoustic impacts of the turbine at this site. 


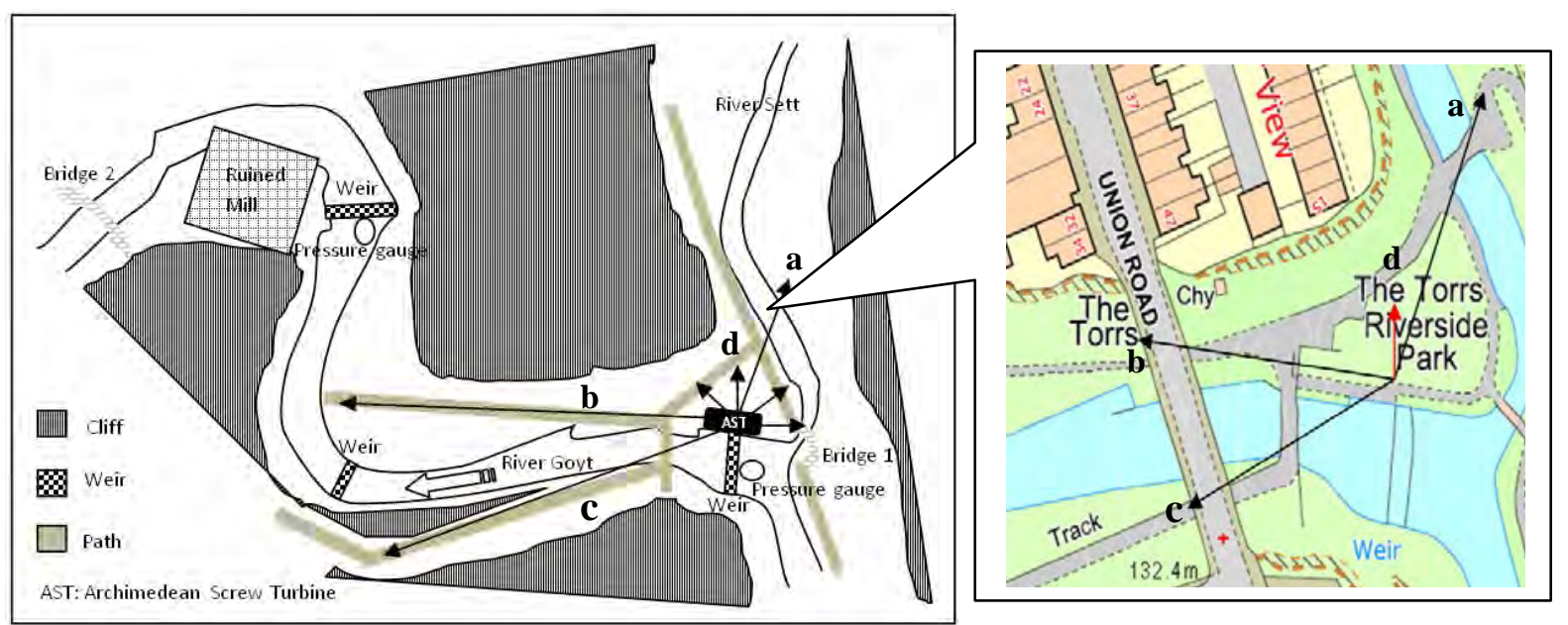

Figure 1. Location of the RAS studied, including the positions of the sampling transects (arrows) $a, b$ and $c$, short red arrow is transect $d$. also shown is the positions of the pressure gauge sensors (for future work), and the location of the injection (Bridge 1), and sampling points (Bridge 2)
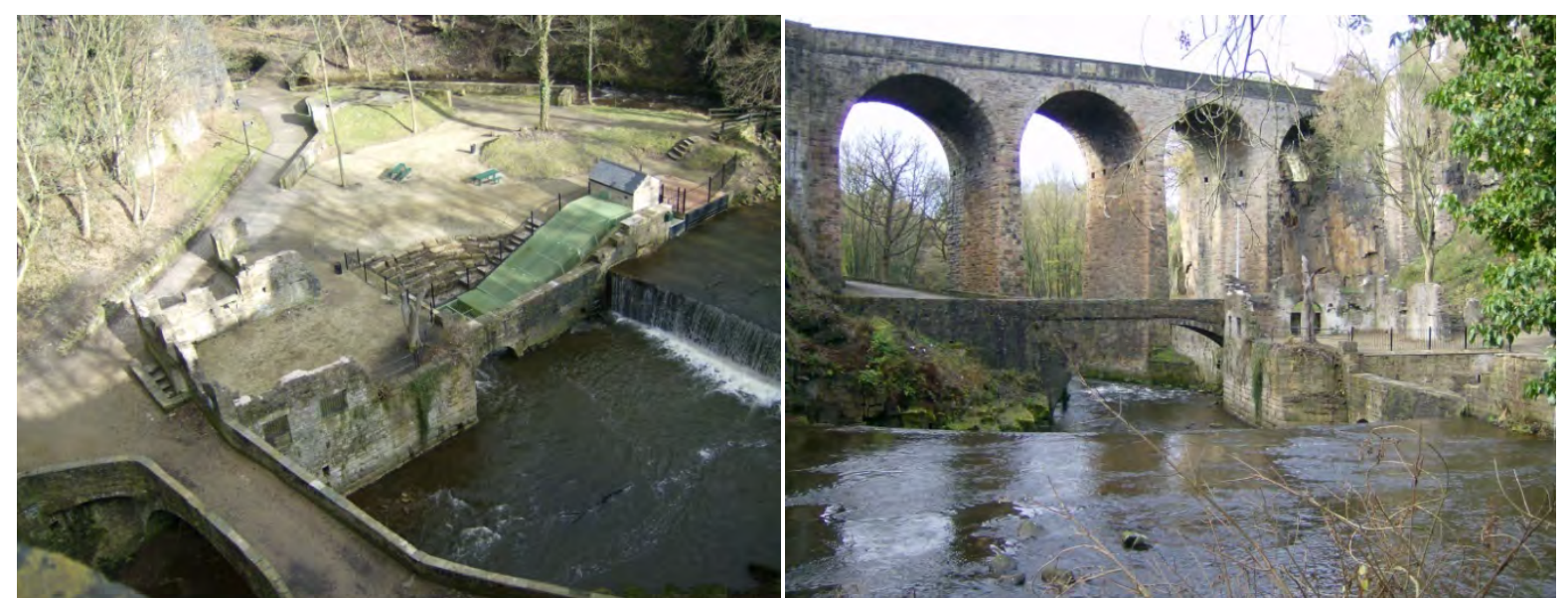

Figure 2. (Left) plan view photo of the RAS at New Mills and (right) a photo looking across the top of the weir to the angled transect (left-hand arch) and same axis (second arch in from right) NB: the bridge is indicative of the stone cliff heights around the site.

Sound Pressure Level (SPL) samples were taken (unweighted Leq) at each point along the transects using Class 1, MP231 microphones and WinMLS 2008. This was repeated when the RAS was running, and when all the water was diverted over the weir and the fish pass. A laser range finder and tape measure were used to give accurate distance of the sampling points from the weir and RAS for accurate sound propagation calculations and soundscape analysis. Processing of the acoustic samples was undertaken in the lab using WinMLS 2008. The main acoustic assumption is that the background soundscape is the same as when the screw is operational.

\section{Results \& Discussion}

It is noted that in this paper, only limited results available are presented, and further measurements are being made. However, the results are of interest as there is no known data published for the sound propagation from RASs in the literature.

At a distance of $90 \mathrm{~m}$, the effects of other weirs downstream from the site were found to mask the sound from the RAS. Therefore, data from the $90 \mathrm{~m}$ samples are not analysed further. Figure 3 shows the SPL at increasing distances from the RAS along transect (d). As expected, 
higher frequencies attenuate at a greater rate, see figure 3 . The attenuation along distance is significant, and at a typical frequency, $500 \mathrm{~Hz}$, the SPL attenuation is about $10 \mathrm{~dB}$.

Observations of 1/3 octave plots and signals, figures 4, 5 and 6 and recordings from the near field, transect (d); indicate a near white noise soundscape environment. By this, it is meant that the sound environment sounds like white noise. This near white noise is generated mainly by the water falling over the broad crest weir. Further to this a noticeable drop in amplitude in the signal can be observed with distance and between on and off, though less so. The spectrum plots of zero metres from screw, figure 4, indicate that there is a 3dBA difference between the screw being off and on which in acoustic terms contributes a barely legible amount [7].

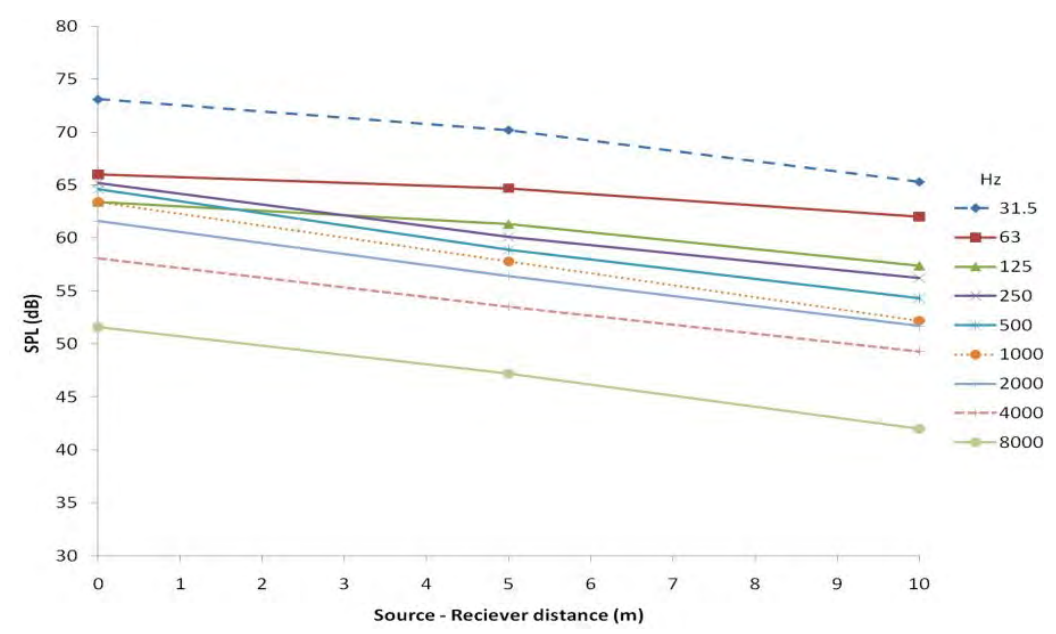

Figure 3. Background SPL when the flow is diverted from the RAS over the weir. Measurements taken along transect d (red arrow, figure 1) of SPL at a range of frequencies with increasing source receiver distance.

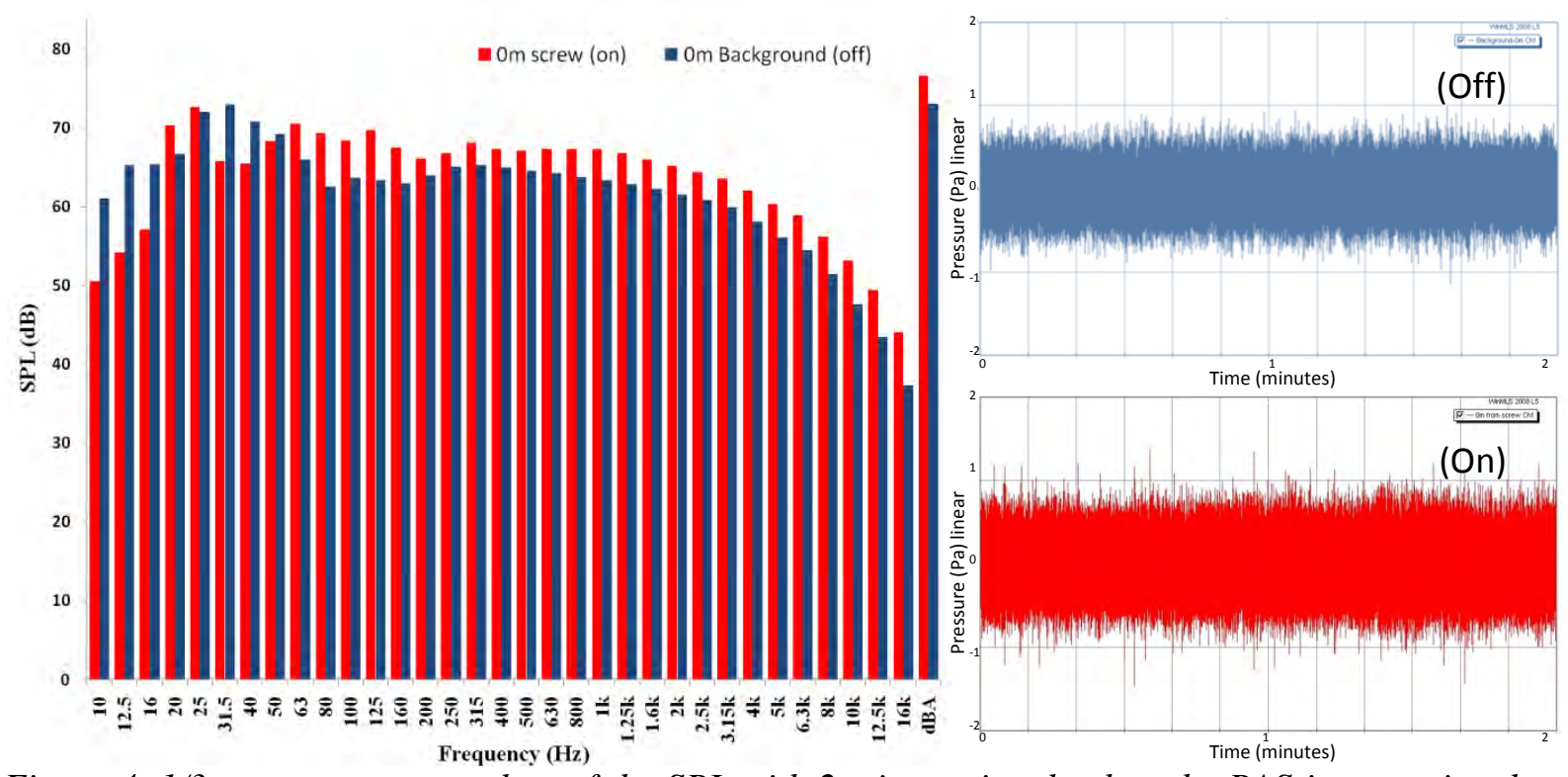

Figure 4. 1/3 octave spectrum plots of the SPL with 2 minute signal, when the RAS is operational at $25 \mathrm{~kW}$ (red) and when the RAS is off, flow is diverted over the weir (blue) taken from directly above the RAS zero metres from screw.

At lower frequencies, the SPL with the RAS being off is $7-10 \mathrm{~dB}$ higher. This might be due to the reduced volume of water falling over the weir when the RAS is running at $25 \mathrm{~kW}$, 
reducing the low frequency component as less water falls into the weir pool. This may also explain the increase in SPL in the mid ranges. A similar pattern can be observed in the plots of samples taken $5 \mathrm{~m}$ from the RAS, figure 5; and again at $10 \mathrm{~m}$, figure 6 . However, there is less of a difference between the $\mathrm{dBA}$ results; with a difference of around $1 \mathrm{~dB}$ and the mid to high frequency ranges being of a similar nature. However, lower frequencies are higher in amplitude during the background sampling than when the screw is operational, which may also be due to reflections from surrounding walls or being more exposed to the weir through an opening in the wall next to the screw and a function of directivity. Figures 4-6 show a decrease in signal amplitude with distance.
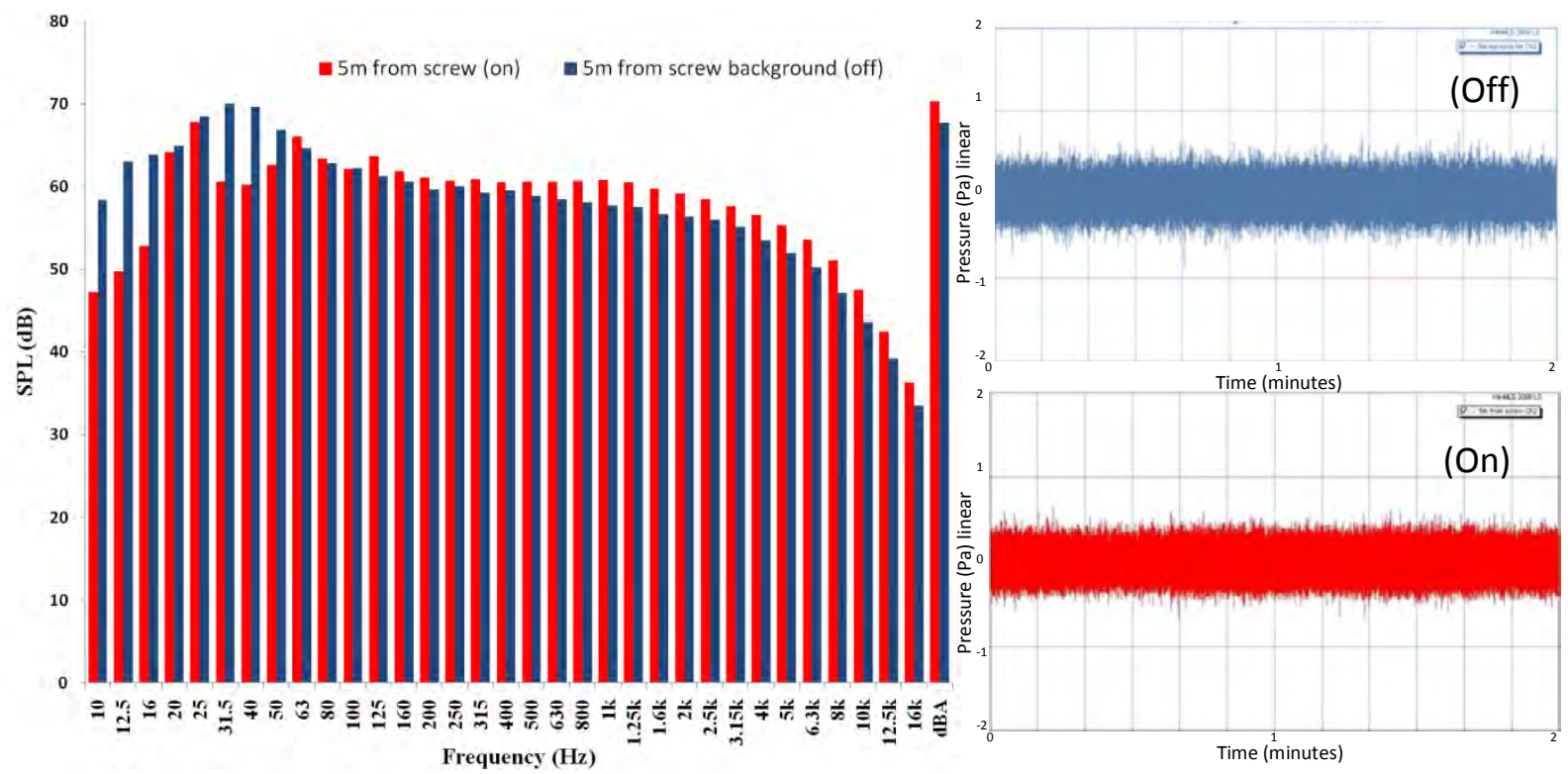

Figure 5. 1/3 octave spectrum plots of the SPL and 2 minute signal, when the RAS is operational at $25 \mathrm{~kW}$ (red) and when the RAS is off, flow is diverted over the weir (blue) at $5 \mathrm{~m}$ from screw.

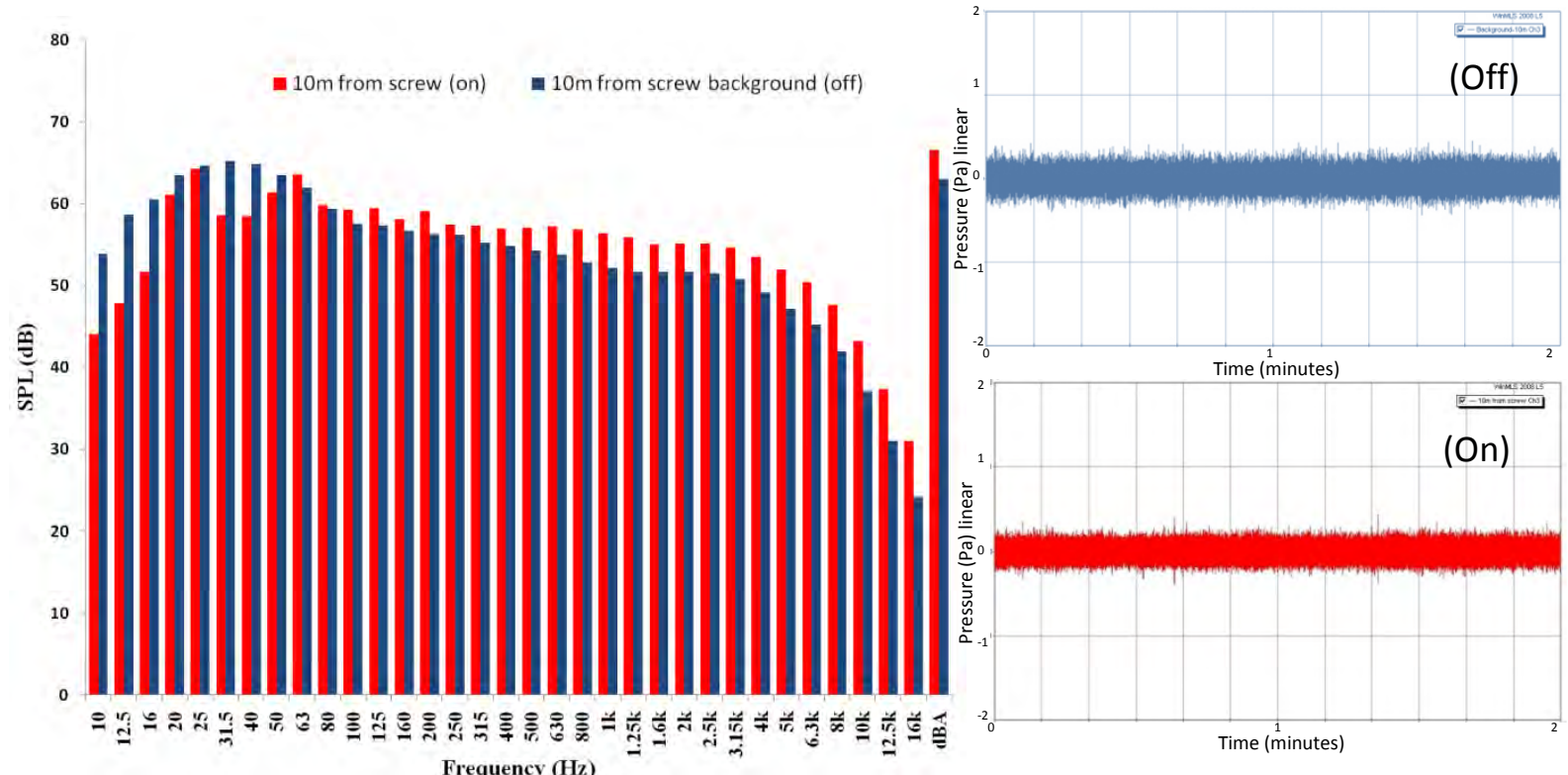

Figure 6. 1/3 octave spectrum plots of the SPL and 2 minute signal when the RAS is operational at $25 \mathrm{~kW}$ (red) and when the RAS is off, flow is diverted over the weir (blue) at $10 \mathrm{~m}$ from screw.

Table 1 and figure 7 show the SPL with increasing distance from the RAS along the three different transects a - c when the flow is diverted over the weir and the RAS is off. The 
amplitudes are higher along transect (c) than (a) or (b), however this transect is located $10 \mathrm{~m}$ from a stone cliff and road bridge, and it was noted on site that reflections were audible. The background data was all collected within a 40 minute period.

Table 1. Sample of background full octaves, SPL (dB) by frequency and transect distance figure 7 , includes the frequencies not shown in this table.

\begin{tabular}{|c|c|c|c|c|c|c|}
\hline 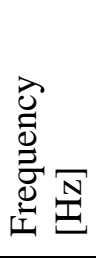 & 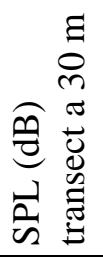 & 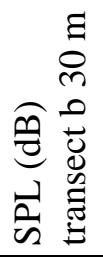 & 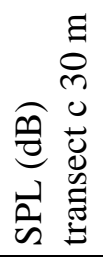 & 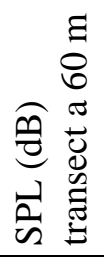 & 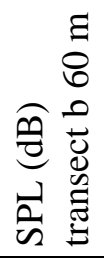 & 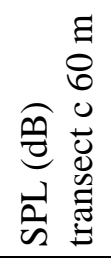 \\
\hline 250 & 51.8 & 55.0 & 61.4 & 44.3 & 53.1 & 55. \\
\hline 1000 & 49.9 & 53.3 & 57.7 & 47.5 & 52.3 & 55.0 \\
\hline 4000 & 46.1 & 49.7 & 53.6 & 40.7 & 45.5 & 50. \\
\hline $\mathrm{dBA}$ & 60.3 & 63.6 & 68.1 & 56.5 & 61.5 & 64 \\
\hline
\end{tabular}

At $30 \mathrm{~m}$ on transect (b); there is a swash noise from water flowing over irregular rocks in the river next to the sample point. There are similar geographical features at this sample point to transect (c), which may increase the reflections in the area, including the large stone bridge, ruined walls and stone cliffs, though these cliffs are situated further away, and the ground is generally softer and grass covered between. There is an increase at $125 \mathrm{~Hz}$ between the $30 \mathrm{~m}$ and $60 \mathrm{~m}$ sampling points on this axis (b). This may be related to other sound sources in the area, such as weirs present further downstream, or reflections in the area. It should also be noted that the large stone bridge near to the sampling point (Figure 2), is a road traffic bridge and this may explain the greater SPL low frequency results.

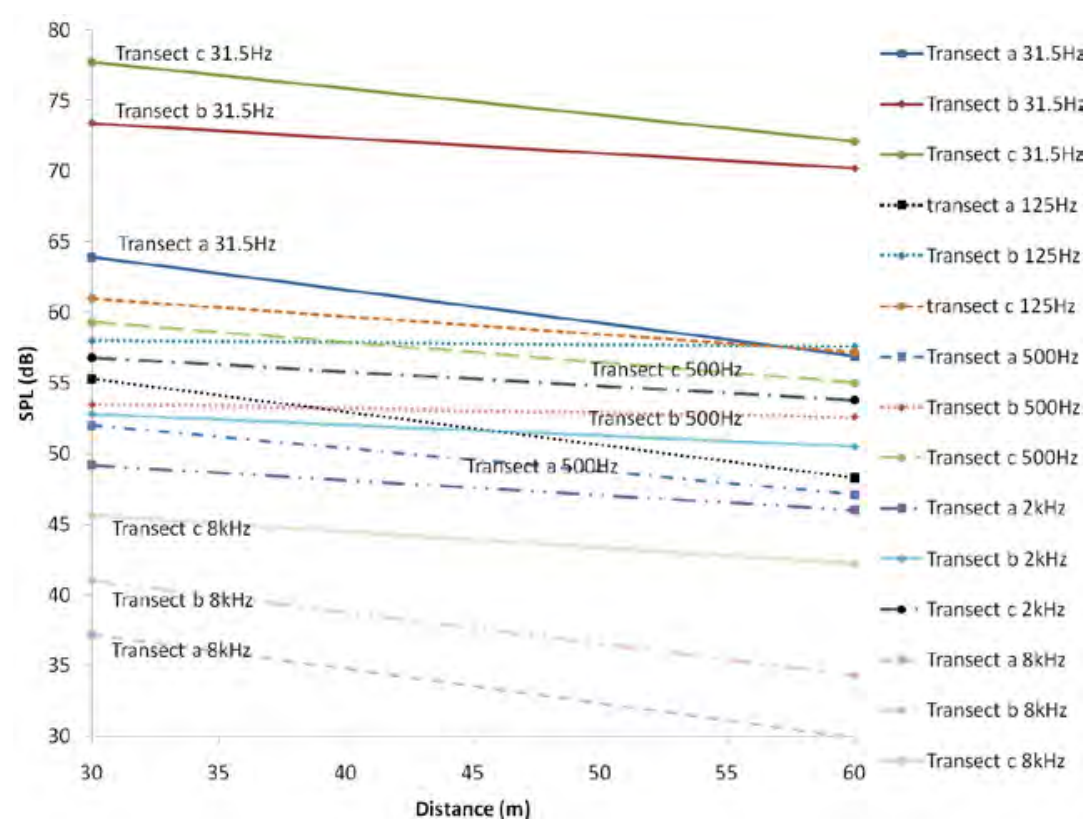

Along transect (a), running perpendicular to the RAS, the results taken at $30 \mathrm{~m}$ and $60 \mathrm{~m}$ sample points are noticeably lower in amplitude than (b) and (c) see figure 7 and table 1. As with the previous background plots figures 3 , $7 \& 8$, the SPL of $31.5 \mathrm{~Hz}$ is higher than that with the screw operational, see figure 9. Figures 8 and 9 compare the SPL measured along transect (d) when the RAS is both on and off.

Figure 7. Example frequencies of the observed attenuation and SPL along transect $a, b$ and $c$ while the turbine is off. Lines between points are for demonstration purposes only and to aid pattern identification. The standard equation for attenuation of a line source with distance [11] was performed at $45 \mathrm{~m}$ and it was found that deviation from the theoretical values is -1.6 to $+2.1 \mathrm{~dB}$.

With a doubling of distance between 30 and $60 \mathrm{~m}$, in free-field conditions attenuation would be $3 \mathrm{~dB}$. Half the frequencies measured have higher attenuation levels than the $3 \mathrm{~dB}$ whilst the other frequencies attenuate at a lower rate. It is thought that these differences are a function of the sampling environment as no corrections were added to the data, e.g. surface roughness differences or directivity. The variation in SPL differs depending on the frequency from 
$0.1 \mathrm{~dB}$ to $9.1 \mathrm{~dB}$, with an average difference between background frequencies and operational frequencies of $4.5 \mathrm{~dB}$ at $0 \mathrm{~m}, 3.3 \mathrm{~dB}$ at $5 \mathrm{~m}$ and $1.6 \mathrm{~dB}$ at $10 \mathrm{~m}$. At $31.5 \mathrm{~Hz}$ the SPL when the RAS is not operational is greater than when it is. These results are for a period when river flow enables the RAS to produce $25 \mathrm{~kW}$; further research is required to understand the generation of noise at a range of flows and electrical power outputs, and to validate the results presented.

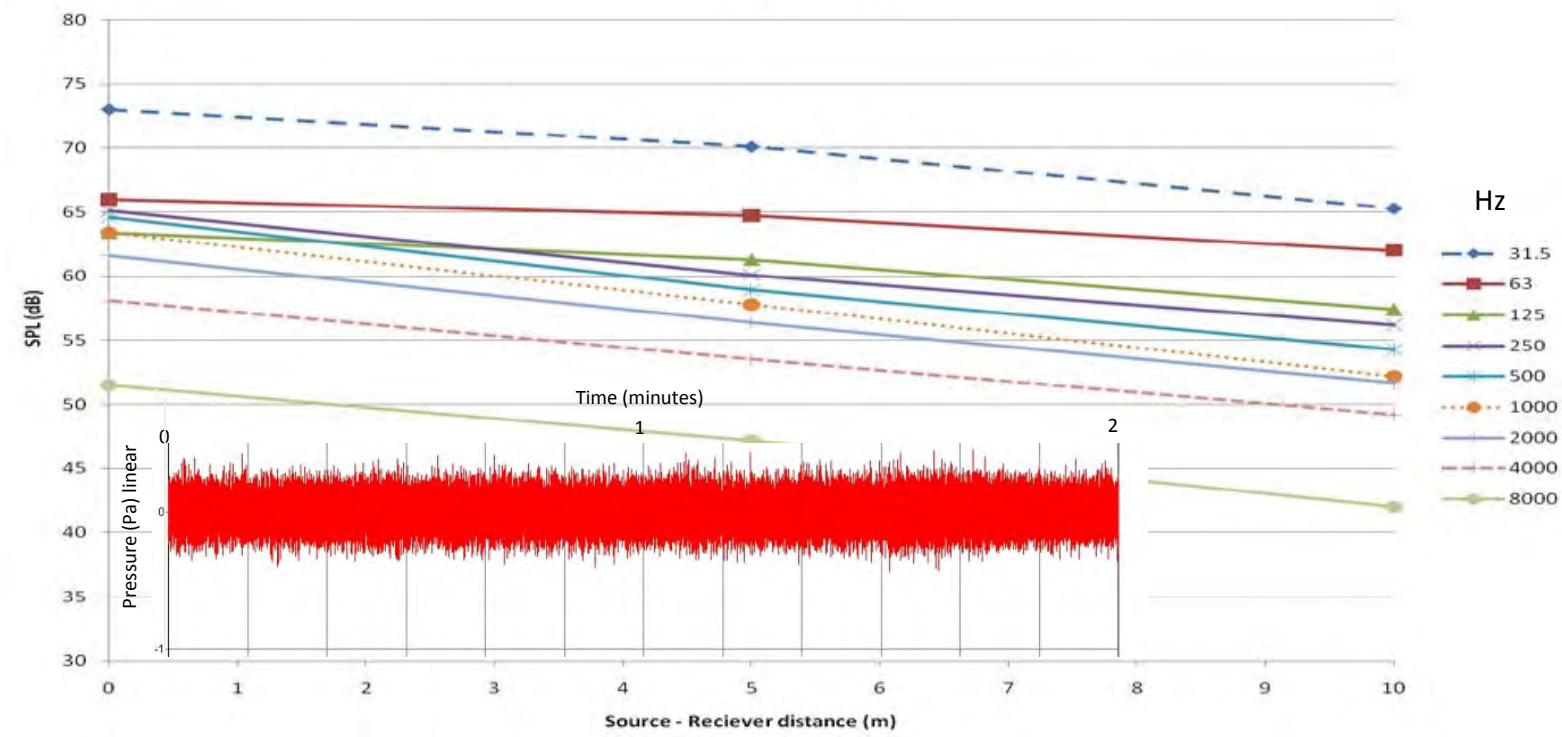

Figure 8. SPL by frequency from 0-10 whilst the turbine is off along transect a, where the insert is the 2 minute sample of the signal measured at $0 \mathrm{~m}$.

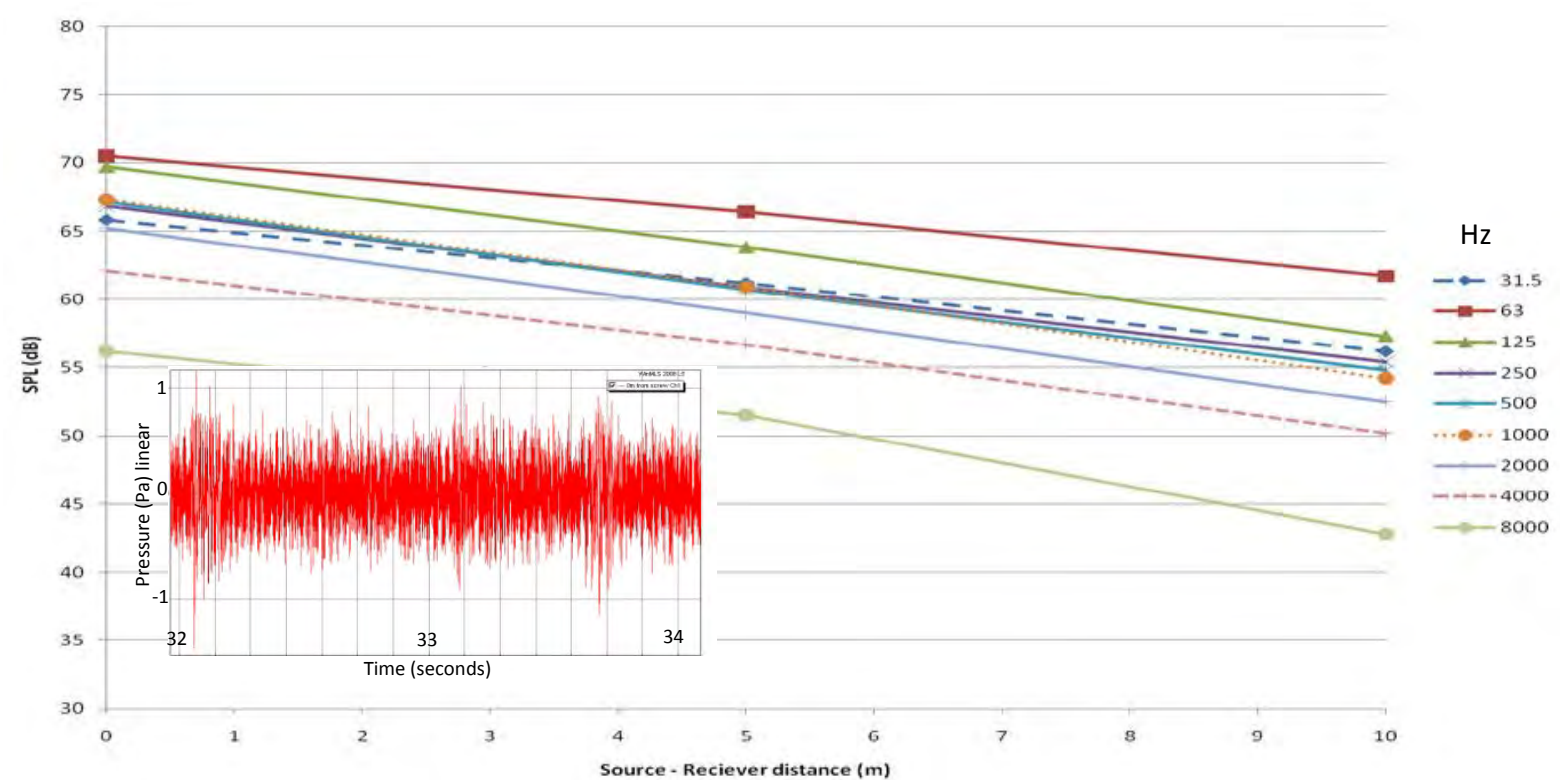

Figure 9. SPL by frequency from 0-10m whilst the turbine is switched on along transect a, where the insert is a 2 second sample of the signal measured at 10m between 32 and 34 seconds. A cyclic impulse can be seen within the signal plotted less than 2 seconds apart. This fits with the tri-blade rotational speed of the RAS which would include the blades entering/exiting the water. 


\section{Conclusions \& Future Work}

Initial results indicate that during normal operation at $25 \mathrm{~kW}$ the screw would be barely perceptible beyond $60 \mathrm{~m}$, and adds just $3 \mathrm{~dB}$ to the background environment and thus in many cases have negligible urban environmental impact running at $25 \mathrm{~kW}$. The weir has a significant masking effect on the RAS sound output. Further to this, the results indicate a directional aspect to the sound propagation from a RAS. However, whether this is a feature of the site or a feature of the RAS design is yet to be determined.

The RAS is not operational below $20 \mathrm{~kW}$, and therefore this study demonstrates the noise propagation at low flows. Future work will consider a range of flows from this increasing to the RAS design capacity of 53kW. Future work will also include a more detailed study of the RAS at New Mills with greater near field sampling and over shorter sampling periods to limit any extraneous noise sources from the results. Evaluation of other RAS sites will be carried to enable modeling and validation of the sound propagation. This will be used to assess the effect of various interventions in reducing noise nuisance from a RAS in an urban setting. Some further results will be presented at the conference.

\section{References}

[1] Driscoll, H.J.R., Micro-hydro power in Dorset: A re-assessment of potential installed capacity. Earth \& E-nvironment, 2008. 3: p. 52-114.

[2] Lior, N., Energy resources and use: The present (2008) situation and possible sustainable paths to the future. Energy, 2009. 35: p. 2631-2638.

[3] International Energy Agency, World Energy Outlook 2008. IEA 2008.

[4] Paish, O., Small hydro power: technology and current status. Renewable \& Sustainable Energy Reviews, 2002. 6(6): p. 537-556.

[5] Frey, G.W. and Linke, D.M., Hydropower as a renewable and sustainable energy resource meeting global energy challenges in a reasonable way. Energy Policy, 2002. 30(14): p. 1261-1265.

[6] Yi, C.-S., Lee, J.-H. and Shim, M.-P., Site location analysis for small hydropower using geo-spatial information system. Renewable Energy, 2010. 35(4): p. 852-861.

[7] Watson, R. and Downey, O., The Little Red Book of Acoustics: A Practical Guide. 2nd ed. 2008: Blue Tree Acoustics. 